\title{
MicroRNA-16 sensitizes breast cancer cells to paclitaxel through suppression of IKBKB expression
}

\author{
Xueyuan Tang ${ }^{1,4}$, Long Jin ${ }^{1}$, Peiguo Cao ${ }^{1}, \mathrm{Ke} \mathrm{Cao}^{1}$, Chenghui Huang ${ }^{1}$, Yanwei Luo ${ }^{3,4}$, \\ Jian Ma ${ }^{3,4}$, Shourong Shen ${ }^{2,4}$, Ming Tan ${ }^{5}$, Xiayu Lí ${ }^{2,4}$, Ming Zhou ${ }^{3,4}$ \\ ${ }^{1}$ Department of Oncology, The Third Xiangya Hospital of Central South University, Changsha, Hunan, China \\ ${ }^{2}$ Department of Gastroenterology, The Third Xiangya Hospital of Central South University, Changsha, Hunan, China \\ ${ }^{3}$ The Key Laboratory of Carcinogenesis of The Chinese Ministry of Health and The Key Laboratory of Carcinogenesis and \\ Cancer Invasion of The Chinese Ministry of Education, Cancer Research Institute, Central South University, Changsha, \\ Hunan, China \\ ${ }^{4}$ Hunan Key Laboratory of Nonresolving Inflammation and Cancer, Disease Genome Research Center, The Third Xiangya \\ Hospital, Central South University, Changsha, Hunan, China \\ ${ }^{5}$ Mitchell Cancer Institute, University of South Alabama, Mobile, Alabama, USA \\ Correspondence to: Ming Zhou, email: zhouming2001@163.com \\ Xiayu Li, email: lixiayu@163.com
}

Keywords: miR-16, IKBKB, Taxol, breast cancer, chemosensitivity

Received: October 08, $2015 \quad$ Accepted: February 29, 2016

Published: March 14, 2016

\section{ABSTRACT}

Paclitaxel (Taxol) is an effective chemotherapeutic agent for treating breast cancer patients. However, chemoresistance is a major obstacle in cancer treatment. Here, we showed that overexpression of miR-16 promoted Taxol-induced cytotoxicity and apoptosis in breast cancer cells. Furthermore, IKB kinase $\beta$ (IKBKB) was identified as a direct target of miR-16. Up-regulation of IKBKB suppressed Taxol-induced apoptosis and led to an increased resistance to Taxol, and restoring IKBKB expression in miR-16-overexpressing breast cancer cells recovered Taxol resistance. Moreover, miR-16 was highly expressed in Taxol-sensitive breast cancer tissues compared with Taxol-resistant tissues, and there was an inverse correlation between miR-16 expression and IKBKB expression in breast cancer tissues. The expression levels of miR-16 were negatively associated with $T$ stages, whereas the expression of IKBKB was positively correlated with $\mathrm{T}$ stages, lymph node metastasis and clinical stages. Taken together, our data demonstrates that miR-16 sensitizes breast cancer cells to Taxol through the suppression of IKBKB expression, and targeting miR-16/IKBKB axis will be a promising strategy for overcoming Taxol resistance in breast cancer.

\section{INTRODUCTION}

Breast cancer is the most common malignancy in women and the leading cause of cancer-related death worldwide, with 232,340 new cases annually [1]. Paclitaxel (Taxol), an effective mitotic inhibitor, is commonly used in the treatment of breast cancer as well as other tumors, such as ovarian, prostate and non-small cell lung cancer $[2,3]$. The major mechanism underlying the anti-tumor activity of Taxol has been ascribed to its ability to interfere with microtubule dynamics through binding to the $\beta$-subunit of microtubule $\alpha-\beta$ tubulin heterodimer and inducing apoptosis by directly interacting with mitochondrial membrane proteins [4,5]. However, despite its widespread usage and infrequent side effects, the clinical efficacy of Taxol in the treatment of breast cancer is often compromised by the emergence of Taxol resistance, which typically appears following a couple cycles of Taxol based chemotherapy. The up-regulation of P-glycoprotein and related drug efflux pumps [6-9] and the altered expression of tubulin isotypes, particularly $\beta$ III-tubulin $[10,11]$, have been strongly implicated in Taxol resistance. However, the exact mechanisms responsible for the development of Taxol resistance remain elusive.

MicroRNAs (miRNAs) are endogenous, 18-25 nucleotide, non-coding, single-stranded RNA molecules, 
which play a critical role in a variety of biological processes, including proliferation, differentiation, migration, cell cycle and apoptosis $[12,13]$. In recent years, some miRNAs have been reported to be involved in drug resistance by acting as potential oncogenes or tumor suppressors [14-16]. MicroRNA-16 (miR-16) is located at $13 \mathrm{q} 14$, which also hosts the tumor suppressor miR-16$1 /-15 a$ cluster [17]. Further investigation indicated that miR-16 was frequently deleted or downregulated in solid tumors including breast cancer, which was identified as a tumor suppressor $[18,19]$. MiR-16 participates in cellcycle regulation by targeting multiple cyclin proteins, and it induces apoptosis by targeting Bcl2 [20,21]. MiR16 was found to be down-regulated by almost two-fold in Taxol-resistant breast cancer cells compared with their parental cells via miRNA microarray assays [14]. Therefore, we hypothesized that miR-16 may contribute to Taxol chemosensitivity in breast cancer.

In the present study, we demonstrated that ectopic expression of miR-16 promoted Taxol-induced cytotoxicity and apoptosis in breast cancer cells. Furthermore, IKBKB was identified to be a direct target of miR-16, restoring the expression of IKBKB counteracted miR-16-mediated Taxol sensitivity. Moreover, miR-16 was highly expressed in Taxol-sensitive breast cancer patients and negatively associated with $\mathrm{T}$ stages, whereas IKBKB was lowly expressed in Taxol-sensitive breast cancer and positively correlated with $\mathrm{T}, \mathrm{N}$ and clinical stages. Taken together, these data indicate that miR-16 increases the chemosensitivity of breast cancer to Taxol through suppression of IKBKB expression, and combination of miR-16 targeted gene therapy and Taxol chemotherapy might represent a promising novel clinical strategy for human breast cancer.

\section{RESULTS}

\section{Involvement of miR-16 in Taxol chemosensitivity in breast cancer cells}

To investigate whether the overexpression of miR-16 could sensitize breast cancer cells to Taxol, miR-16 mimics (miR-16) were transfected into two breast cancer cell lines, MDA-MB-231 (Figure 1A, left) and MCF-7 (Figure 1A, right), followed by treatment with Taxol for $48 \mathrm{~h}$. We found that overexpression of miR-16 markedly increased Taxolinduced cell cytotoxicity in both MDA-MB-231 (Figure 1B, left) and MCF-7 cells (Figure 1B, right) compared with the negative control (miR-NC). To confirm and extend our findings, we treated these miR-16-transfected cells with a dose range of Taxol and obtained the similar results in both cell lines (Figure 1C, Figure S1A), and the IC50 values of miR-16-transfected cells were much lower than miR-NC-transfected and mock cells (Figure S1B). Moreover, we found there was a trend that overexpression of miR-16 dramatically enhanced the cytotoxicity of Taxol and inhibited Taxol resistance in a miR-16 dose-dependent manner in both MDA-MB-231 (Figure 1D, left) and MCF7 cells (Figure 1D, right). These results demonstrate a positive correlation between miR-16 expression and Taxol response in breast cancer cells.

Since overexpression of miR-16 increased Taxol sensitivity, we wondered whether down-regulation of miR-16 would confer breast cancer cells resistant to Taxol. Thus, the miR-16 inhibitor (anti-miR-16) was transiently transfected in MDA-MB-231 (Figure 1E, top left) and MCF-7 cells (Figure 1E, top right) followed by treatment with increasing concentrations of Taxol for 48 h. As expected, the knockdown of miR-16 impaired Taxolinduced cytotoxicity in these two cell lines (Figure 1E, bottom). These results demonstrate that miR-16 plays an important role in Taxol-induced chemosensitivity in breast cancer cells.

\section{Involvement of miR-16 in Taxol-induced apoptosis in breast cancer cells}

Taxol is known to exert its anti-tumor effect through induction of apoptosis [22]. Next, we examined whether overexpression of miR-16 was capable of enhancing Taxol-induced apoptosis. Our results showed that more cellular debris and non-viable cells were observed with an inverted microscope in miR-16-transfected MDAMB-231 (Figure 2A, left) and MCF-7 (Figure 2A, right) cells compared with the control groups after treatment of Taxol. Poly (ADP-ribose) polymerase (PARP) is an important marker of apoptosis that is cleaved by caspases during cellular apoptosis $[23,24]$. Therefore, we detected the protein levels of cleaved PARP (c-PARP) by western blot assays in miR-16-transfected or miR-NC-transfected MDA-MB-231 and MCF-7 cells after Taxol treatment. Compared with the negative control, the protein levels of c-PARP were dramatically increased in miR-16transfected cells (Figure 2B). In line with the former results, apoptosis assays with annexin $\mathrm{V}$ staining revealed more apoptotic cells in miR-16-transfected cells after treatment of Taxol (Figure 2C). Conversely, knockdown of endogenous miR-16 impaired Taxol-induced apoptosis in these two cell lines by comparing the protein levels of c-PARP (Figure 2D). These results indicate that miR16 enhances Taxol sensitivity in breast cancer cells by promoting Taxol-induced apoptosis.

\section{IKBKB is a direct target of miR-16 in breast cancer cells}

To elucidate the mechanisms underlying promoting the response of human breast cancer cells to Taxol by miR-16, we used three bioinformatic programs (TargetScan, miRDB and miRanda) to predict the potential target genes of miR-16. All of the three public miRNA databases predicted that IKBKB might be a potential 

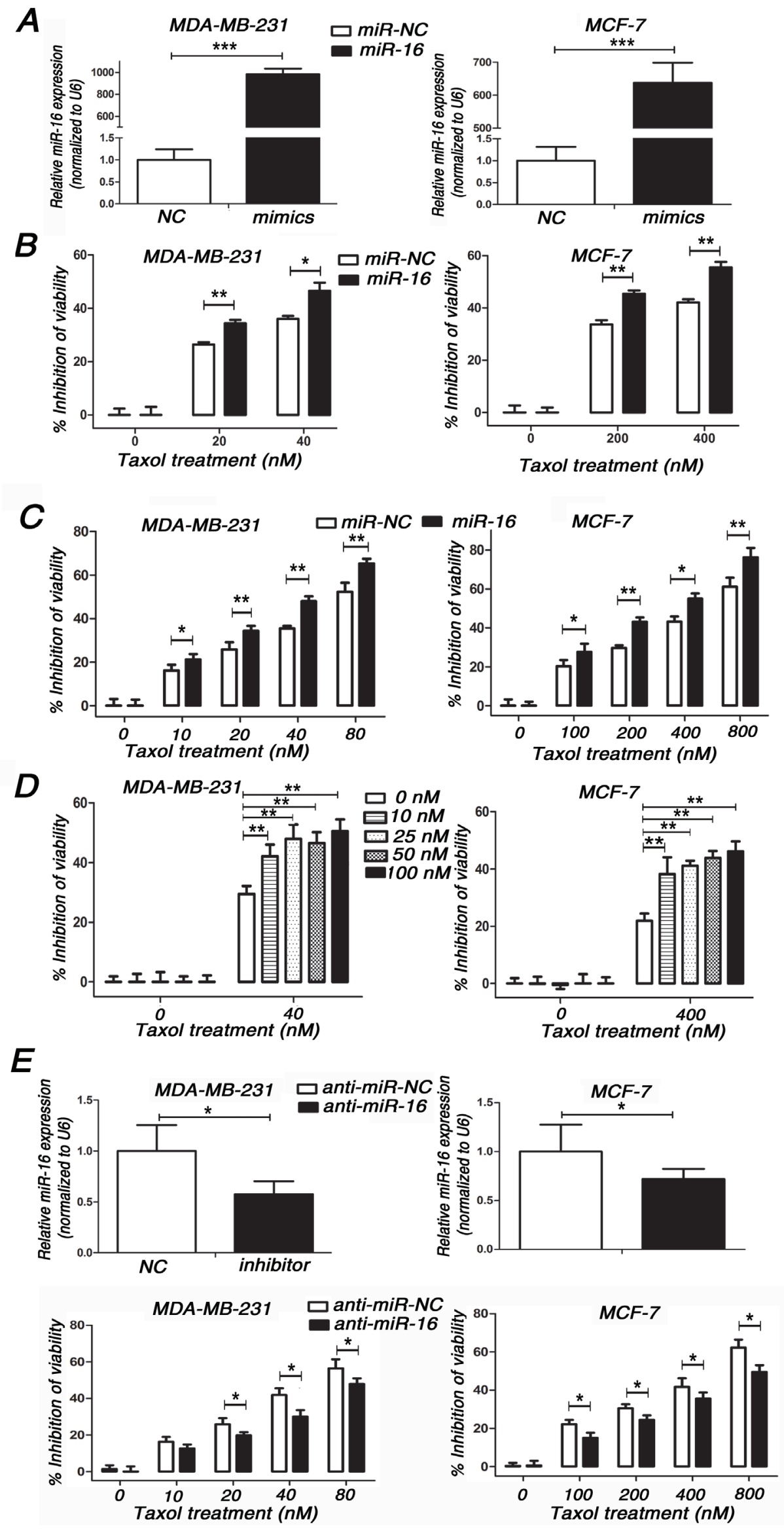

(Continued) 
Figure 1 (Continued): Involvement of miR-16 in Taxol chemosensitivity in breast cancer cells. A. miR-16 levels were detected in MDA-MB-231 and MCF-7 cells transfected with $50 \mathrm{nM}$ miR-16 mimics or $50 \mathrm{nM}$ miR-NC by qRT-PCR. B. MDA-MB-231 and MCF-7 cells transfected with $50 \mathrm{nM}$ miR-16 mimics or $50 \mathrm{nM}$ miR-NC were seeded into 96-well plates and treated with 0, 20, 40 $\mathrm{nM}$ (MDA-MB-231) or 0, 200, $400 \mathrm{nM}$ (MCF-7) Taxol for $48 \mathrm{~h}$. The cell viabilities were detected by MTT assays. C. MDA-MB-231 and MCF-7 cells transfected with $50 \mathrm{nM}$ miR-16 mimics or $50 \mathrm{nM}$ miR-NC were seeded into 96-well plates and treated with 0, 10, 20, 40, 80 nM (MDA-MB-231) or 0, 100, 200, 400, $800 \mathrm{nM}$ (MCF-7) Taxol for $48 \mathrm{~h}$. The cell viabilities were detected by MTT assays. D. MDAMB-231 and MCF-7 cells transfected with 0, 10, 25, 50, $100 \mathrm{nM}$ miR-16 mimics or equal dose of miR-NC were seeded into 96-well plates and treated with 0, $40 \mathrm{nM}$ (MDA-MB-231) or 0, $400 \mathrm{nM}$ (MCF-7) Taxol for 48 h. The cell viabilities were detected by MTT assays. E. MDA-MB-231 and MCF-7 cells transfected with $100 \mathrm{nM}$ miR-16 inhibitor or $100 \mathrm{nM}$ anti-miR-NC (top) were seeded into 96-well plates and treated with $0,10,20,40,80 \mathrm{nM}$ (MDA-MB-231) or 0, 100, 200, 400, $800 \mathrm{nM}$ (MCF-7) Taxol for 48 h. The cell viabilities were detected using MTT assays. Data are presented as the percentage of viability inhibition measured in untreated cells. Columns, means of three independent experiments; bars, SE. *, $\mathrm{p}<0.05,{ }^{* *}, \mathrm{p}<0.01, * * *, \mathrm{p}<0.001$.

target for miR-16, and the 3'-UTR of IKBKB contains a highly conserved binding site for miR-16 from position 603 to 610 (Figure 3A). We further demonstrated that the overexpression of miR-16 significantly down-regulated the protein level of IKBKB in a dose-dependent manner in MDA-MB-231 and MCF7 cells (Figure 3B and 3C). In contrast, knockdown of miR-16 up-regulated the expression of IKBKB in both cell lines (Figure 3D). Next, qPCR was performed to investigate the effect of miR16 on IKBKB mRNA expression in MDA-MB-231 and MCF-7 cells. As expected, overexpression of miR-16 significantly decreased the expression of IKBKB mRNA (Figure 3E), whereas knockdown of miR-16 increased the mRNA levels of IKBKB compared with control cells in both MDA-MB-231 and MCF7 cell lines (Figure 3F). The above results support that miR-16 could negatively regulate the expression of $\mathrm{IKBKB}$ at both $\mathrm{mRNA}$ and protein levels.

As miR-16 could negatively regulate the expression of IKBKB, we wanted to know whether miR-16 could directly target IKBKB. Therefore, dual-luciferase reporter analysis was performed to detect whether miR-16 directly bound to the 3'-UTR of IKBKB mRNA. As shown in Figure $3 \mathrm{G}$, overexpression of miR-16 decreased the luciferase activity of the reporter gene with wild-type 3'UTR (3'-UTR-wt) of IKBKB, while no inhibitory effect was detected with the mutated 3'-UTR (3'-UTR-mut) of IKBKB. On the contrary, knockdown of miR-16 increased the luciferase activity of the reporter gene with wild-type 3'-UTR (3'-UTR-wt) of IKBKB, while no inhibitory effect was detected with the mutated 3'-UTR (3'-UTRmut) of IKBKB (Figure 3H). These data support that IKBKB is a direct target of miR-16 in breast cancer cells.

\section{IKBKB plays a critical role in Taxol-induced apoptosis}

IKBKB, a component of NF- $\kappa \mathrm{B}$ signaling, has been proven to participate in apoptosis [25]. However, its role in Taxol-induced cell cytotoxicity and apoptosis is not well understood. Thus, we transfected an IKBKB overexpression plasmid into MDA-MB-231 (Figure 4A, left inset) and MCF-7 (Figure 4A, right inset) cells and subsequently treated these cells with a dose range of
Taxol. Our results demonstrated that the overexpression of IKBKB efficiently inhibited Taxol-induced cell cytotoxicity (Figure 4A). Furthermore, cleaved PARP was dramatically reduced in IKBKB-transfected MDAMB-231 and MCF-7 cells after treatment with Taxol for 48 $\mathrm{h}$ (Figure 4B), suggesting that overexpression of IKBKB suppressed Taxol-induced cell apoptosis. These data were further validated by annexin $\mathrm{V}$ staining (Figure 4C). These results indicates that overexpression of IKBKB could suppress Taxol-induced cell cytotoxicity and apoptosis.

\section{Restoring IKBKB expression counteracts miR- 16-mediated Taxol sensitivity}

Since IKBKB plays a critical role in Taxol-induced cell cytotoxicity and apoptosis, we sought to determine whether miR-16 promoted the response of breast cancer cells to Taxol by suppressing IKBKB expression. Compared with cells transfected with miR-16 mimics alone, MDA-MB-231 and MCF-7 cells transfected with miR-16 mimics plus IKBKB overexpression vector partially restored Taxol-induced cytotoxicity (Figure 5B) and apoptosis (Figure 5A and 5C). Taken together, these results clearly demonstrate that miR-16 could sensitize breast cancer cells to Taxol at least partially through the direct suppression of IKBKB expression.

\section{Higher expression of miR-16 was detected in Taxol-sensitive breast cancer tissues compared with Taxol-resistant tissues}

Since miR-16 was associated with responses of breast cancer cells to Taxol, we wondered whether there was a difference in miR-16 expression levels between Taxol-sensitive and Taxol-resistant breast cancer tissues. Therefore, in situ hybridization (ISH) was performed to investigate the expression levels of miR-16 in paraffinembedded breast cancer samples. Computed tomography (CT) changes before and after Taxol treatment were used to differentiate Taxol-sensitive and resistant patients (Figure 6A). Our results reveal that the expression of miR16 was higher in 27 Taxol-sensitive breast cancer samples than in the 15 Taxol-resistant samples (48\%, 13/27 vs. $13 \%, 2 / 15 ; \mathrm{p}<0.05$; Figure $6 \mathrm{~A}$ and $\mathrm{B}$ ). 

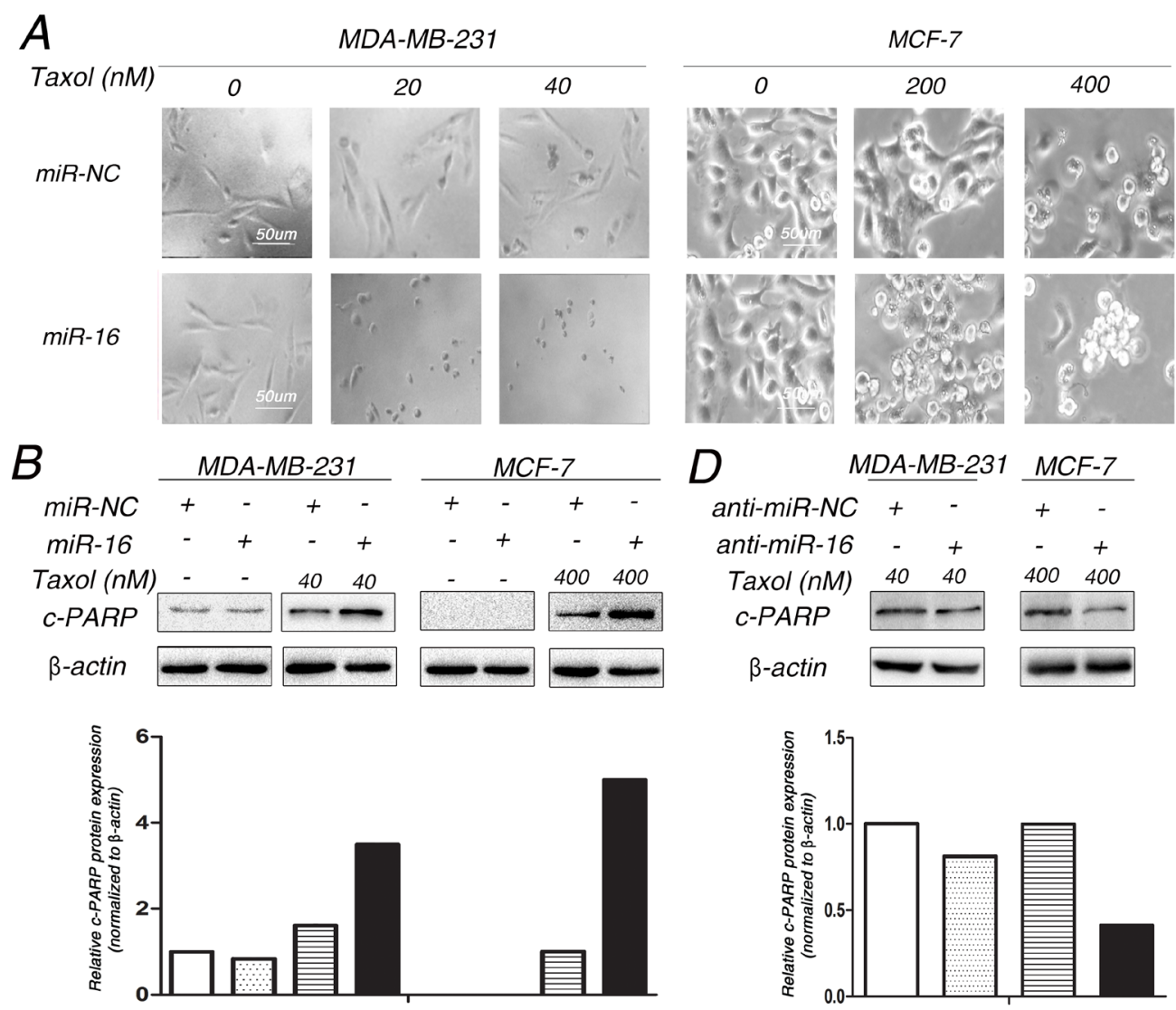

C
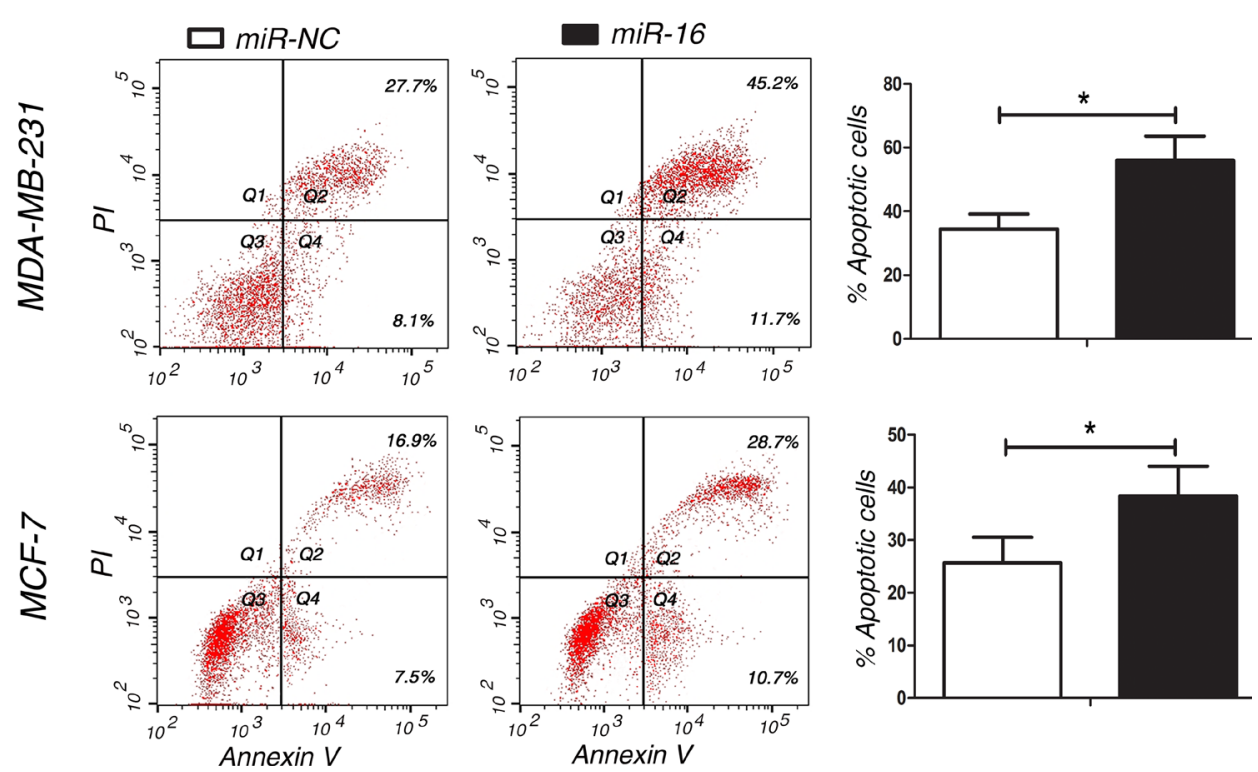

Figure 2: Involvement of miR-16 in Taxol-induced apoptosis in breast cancer cells. A. MDA-MB-231 and MCF-7 cells transfected with $50 \mathrm{nM}$ miR-16 mimics or $50 \mathrm{nM}$ miR-NC were treated with 0, 20, $40 \mathrm{nM}$ (MDA-MB-231) or 0, 200, 400 nM (MCF-7) Taxol for $48 \mathrm{~h}$. The cellular morphologies were visualized using a phase-contrast microscope. B-C. MDA-MB-231 and MCF-7 cells were transfected with $50 \mathrm{nM}$ miR-NC or miR-16 mimics and then treated with 40 and $400 \mathrm{nM}$ Taxol for $48 \mathrm{~h}$, respectively. Cell lysates were extracted for western blotting using an antibody against c-PARP (B), or cells were collected for annexin V staining and flow cytometry assays (C). The gray density was quantified using the ImageJ software and normalized to $\beta$-actin. The percentage of apoptotic cells is represented in a bar diagram from three independent experiments. D. MDA-MB-231 and MCF-7 cells transfected with $100 \mathrm{nM}$ anti-miRNC or miR-16 inhibitor were treated with 40 and $400 \mathrm{nM}$ Taxol for $48 \mathrm{~h}$, respectively. Cell lysates were extracted for western blotting using an antibody against c-PARP. $\beta$-actin was used as an internal control. Columns, means of three independent experiments; bars, S.E. $*, \mathrm{p}<0.05, * *, \mathrm{p}<0.01$. 


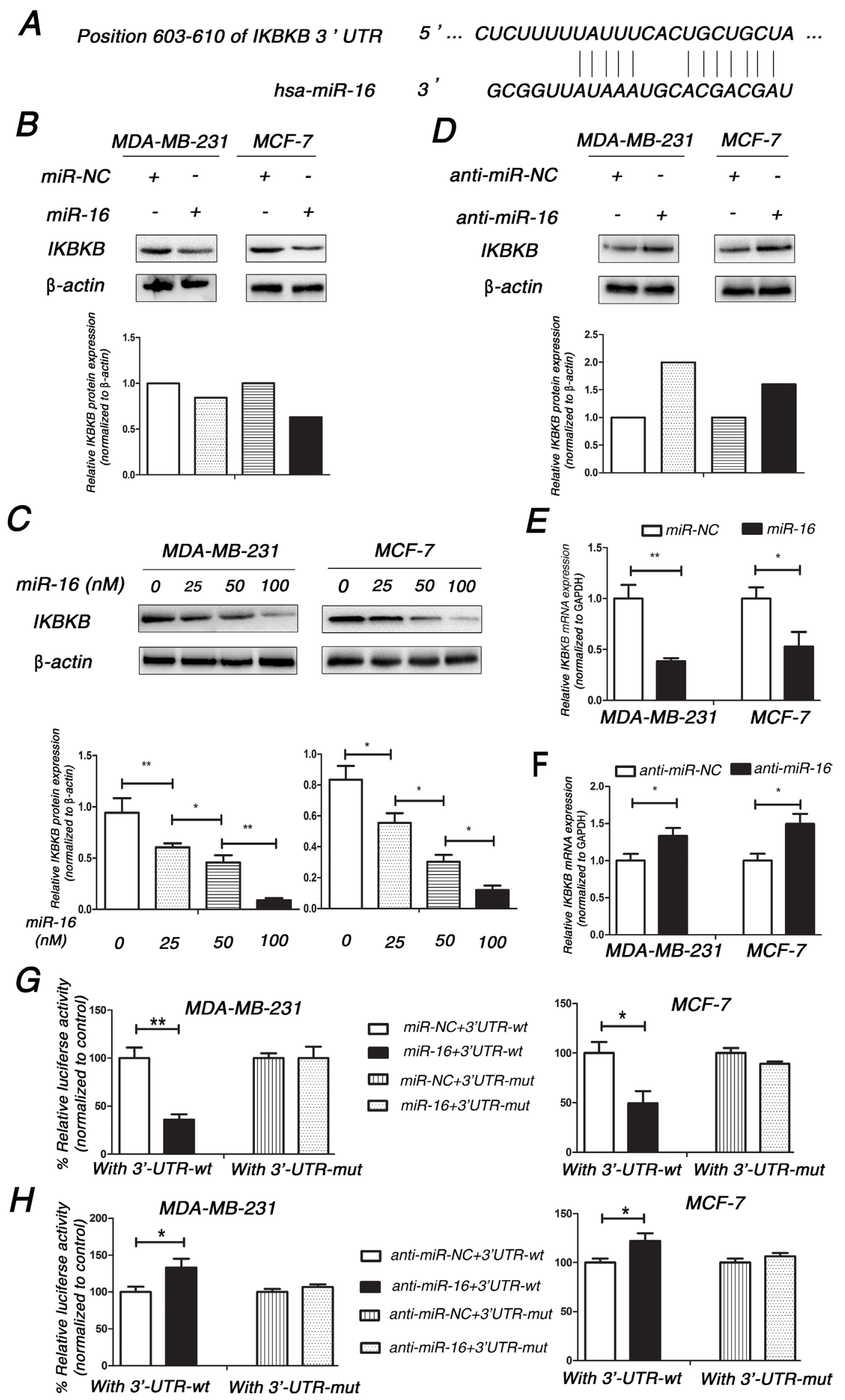

(Continued) 
Figure 3 (Continued): IKBKB is a direct target of miR-16 in breast cancer cells. A. Schematic description of interaction between IKBKB and miR-16. B. MDA-MB-231 and MCF-7 were transfected with $50 \mathrm{nM}$ miR-NC or miR-16 mimics. Cell lysates were prepared for western blotting with an antibody against IKBKB $48 \mathrm{~h}$ after transfection. $\beta$-actin was used as a loading control. The gray density was quantified using the ImageJ software and normalized to $\beta$-actin. C. $0,25,50,100 \mathrm{nM}$ miR-16 mimics were transfected into MDA-MB-231 and MCF-7 cells, and then the expression of IKBKB was detected by western blotting assay as (B) performed. D. MDA-MB-231 and MCF7 were transfected with $100 \mathrm{nM}$ anti-miR-NC or miR-16 inhibitor, and then similar experiments as in (B) were performed. E. MDA-MB-231 and MCF-7 were transfected with $50 \mathrm{nM}$ miR-NC or miR-16 mimics. Total cellular RNA was collected and IKBKB mRNA levels were measured by qRT-PCR $24 \mathrm{~h}$ after transfection. The relative mRNA levels of IKBKB were shown in the bar diagram from three independent experiments and normalized to GAPDH. F. MDA-MB-231 and MCF-7 were transfected with $100 \mathrm{nM}$ anti-miR-NC or miR-16 inhibitor, and similar experiments as in (E) were performed and analyzed. G. MDA-MB-231 and MCF-7 were co-transfected with pMIR-IKBKB-3'UTR-wt or pMIR-IKBKB-3'UTR-mut and $50 \mathrm{nM}$ miR-16 mimics using Lipofectamine 3000 reagent. Luciferase activity was measured $48 \mathrm{~h}$ after transfection. The pRL-TK vector was used as an internal control. The results were expressed as relative luciferase activity (firefly luc/renilla luc). H. MDA-MB-231 and MCF-7 cells were co-transfected with pMIR-IKBKB-3'UTRwt or pMIR-IKBKB-3'UTR-mut and $100 \mathrm{nM}$ miR-16 inhibitor using Lipofectamine 3000 reagent, and similar experiments as in (G) were performed and analyzed. Columns, means of three independent experiments; bars, S.E. *, $\mathrm{p}<0.05,{ }^{* *}, \mathrm{p}<0.01$.

\section{The association of miR-16 and IKBKB expression with the clinicopathological characteristics of breast cancer patients}

As miR-16 could directly target IKBKB in breast cancer cells, we wondered whether miR-16 expression was negatively associated with IKBKB expression in breast cancer tissues. Therefore, we detected the expression of miR-16 and IKBKB in paraffin-embedded breast cancer samples by in situ hybridization (ISH) and immunohistochemical (IHC) analysis, respectively. We found that miR-16 and IKBKB expression were predominantly positive in the cytoplasm, while they were rarely expressed in the nuclei. Moreover, a significant inverse association was observed between miR-16 and IKBKB expression in breast cancer specimens (Figure 7A and 7B). We then analyzed miR-16 and IKBKB expression and their possible associations with clinicopathological parameters, such as age, pathological classification, pathological grade, tumor size ( $\mathrm{T}$ staging), lymph node metastasis ( $\mathrm{N}$ staging), distant tumor metastasis ( $\mathrm{M}$ staging) and clinical staging (Table 1). The data indicated that miR-16 expression was negatively associated with $\mathrm{T}$ staging (Table 1; Figure 7C and 7E), but it presented a non-significant association with age, pathological classification, pathological grade, N, M and clinical staging. Meanwhile, IKBKB expression was positively correlated with T, N and clinical staging (Table 1; Figure 7D and 7F), but it was non-significantly correlated with age, pathological classification, pathological grade, and $\mathrm{M}$ staging.

\section{DISCUSSION}

Taxol based combination chemotherapy is widely used to treat and extend survival in patients diagnosed with breast cancer [2]. MiR-16 was reported to be involved in chemoresistance of anti-cancer drugs in multiple of caner types by targeting different genes $[26,27]$. Cittelly et al showed that miR-16 could directly down-regulate $\mathrm{Bcl}-2$, subsequently sensitizing breast cancer to the endocrine drug tamoxifen [26]. Huang $\mathrm{N}$ et al found that miR-16 could enhance the chemosensitivity of camptothecin by directly targeting Rictor through autophagy signaling in HeLa cells [27]. In our study, miR-16 was found to enhance Taxol-induced cytotoxicity and chemosensitivity in breast cancer cells. As Taxol is known to exert its anti-tumor effect through induction of apoptosis [22], we further demonstrated that although miR-16 has no significant effect on apoptosis in breast cancer cells (Figure S2), miR-16 could increase Taxolinduced apoptosis, and this pro-apoptotic effect was a key mechanism of miR-16-mediated Taxol sensitivity in breast cancer cells. Previous studies have also demonstrated that miR-16 could induce apoptosis in chronic lymphocytic leukemia (CLL) [28].

I $\mathrm{B}$ kinase $\beta$ (IKBKB) was identified as a component of NF- $\mathrm{KB}$ signaling and is highly active in various malignancies including acute myeloid leukemia, melanoma, breast and pancreatic cancer [29-32]. The breast cancer MDA-MB-453 cell line with ectopic expression of IKBKB has a higher proliferation rate than its IKBKB-negative counterpart [33]. Song et al validated that miR-218 inhibited the invasive ability of glioma cells through the direct downregulation of IKBKB [34], suggesting that IKBKB could effectively regulate the behaviors of cancer cells. In accordance with previous data, we identified IKBKB as a direct target of miR-16, overexpression of IKBKB could decrease Taxol-induced cytotoxicity and apoptosis in breast cancer cells. To our knowledge, this is the first report to demonstrate a direct link between IKBKB expression and Taxol sensitivity in cancer cells. Furthermore, our results validated an inverse correlation between miR16 expression and IKBKB expression in breast cancer tissues. Importantly, we found that miR-16 contributed to Taxol chemosensitivity through the suppression of IKBKB expression, which partially explained miR-16-mediated Taxol cytotoxicity, indicating that the miR-16-IKBKB axis was involved in Taxol sensitivity in breast cancer cells. Although restoring the expression of IKBKB could only partially abrogate Taxol-induced cell cytotoxicity and apoptosis, this might be explained by the diversity of 


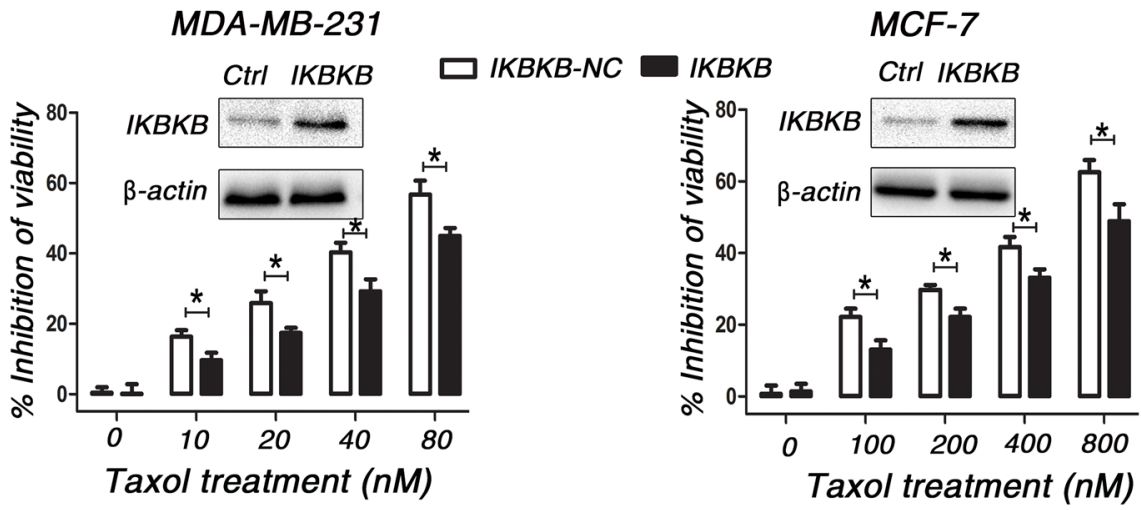

$B$
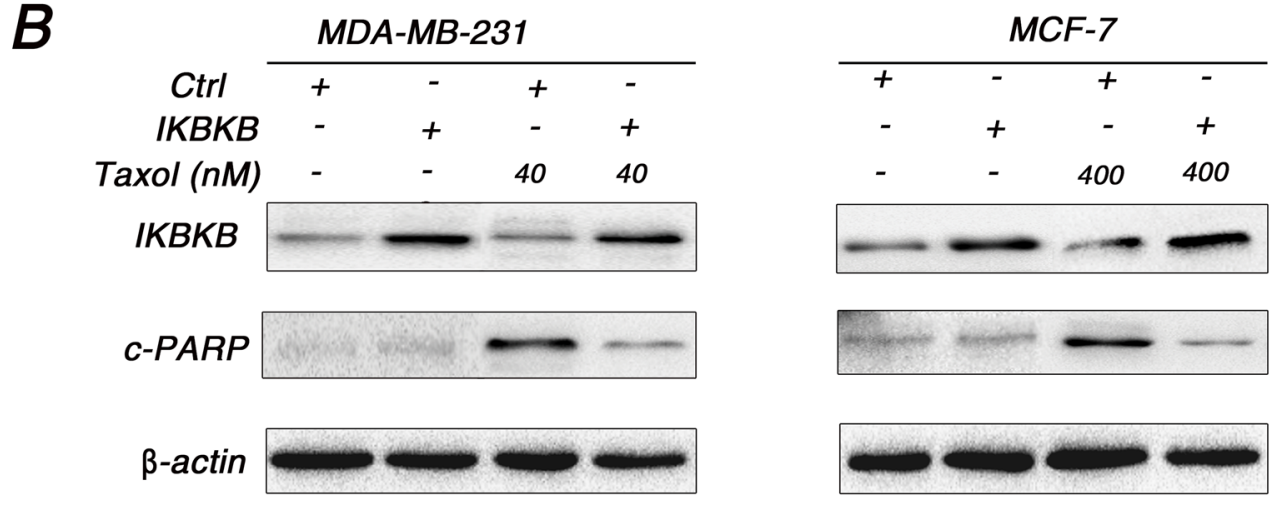

$C$
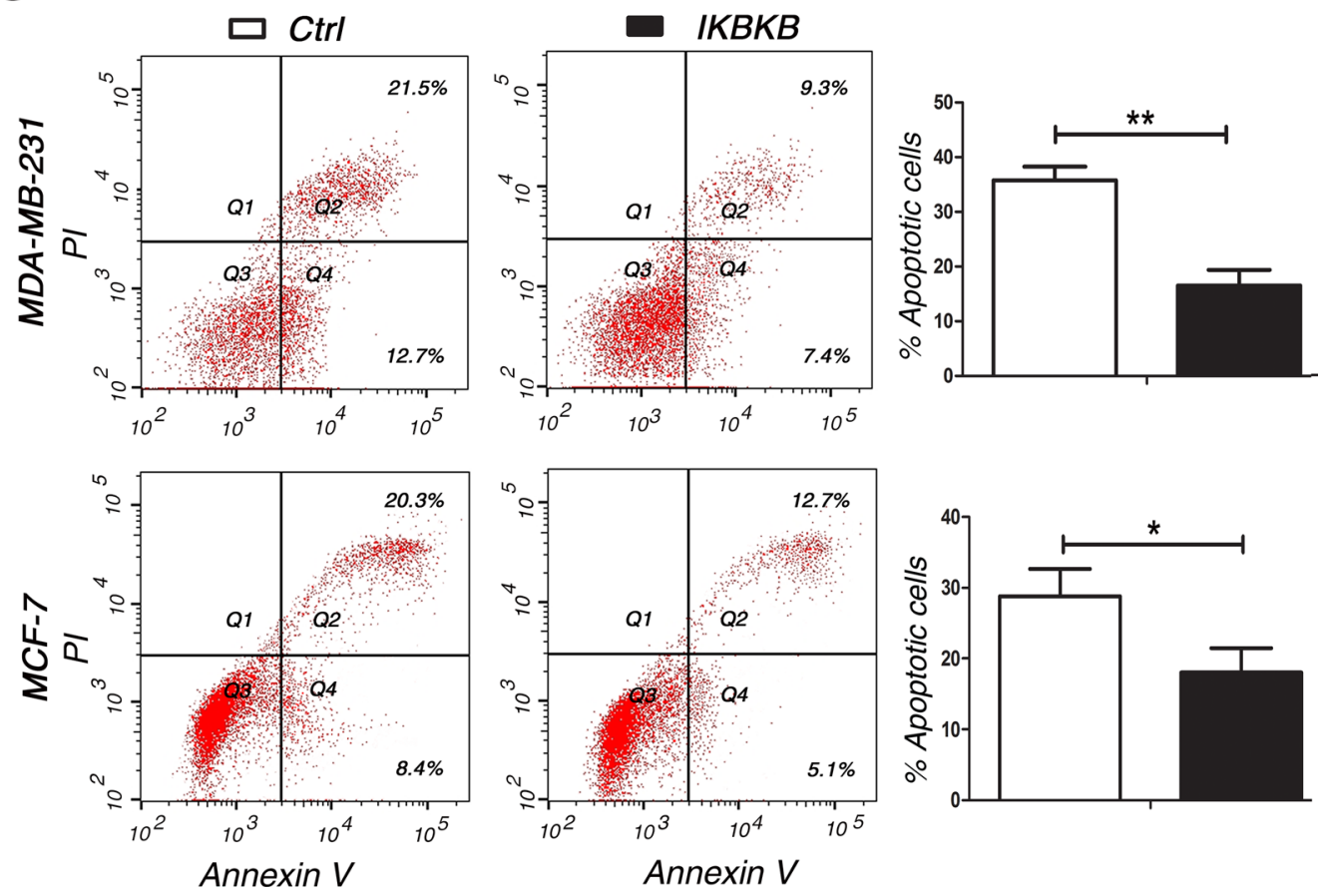

Figure 4: IKBKB plays a critical role in Taxol-induced apoptosis. A. MDA-MB-231 and MCF-7 cells transfected with blankplasmid or IKBKB (inset) overexpression plasmid were seeded into 96-well plates and treated with 0, 10, 20, 40, 80 nM (MDA-MB-231) or $0,100,200,400,800 \mathrm{nM}$ (MCF-7) Taxol for $48 \mathrm{~h}$. The inhibition of cell viabilities was detected using MTT assays. Columns, means of three independent experiments; bars, S.E. *p<0.05. B-C. MDA-MB-231 and MCF-7 cells were transfected with blank-plasmid or IKBKB overexpression plasmid and then treated with 40 and $400 \mathrm{nM}$ Taxol for $48 \mathrm{~h}$, respectively. Cell lysates were extracted for western blotting using antibodies against c-PARP and IKBKB (B), or cells were collected for annexin V staining and flow cytometry assays (C). The percentage of apoptotic cells is represented in a bar diagram from three independent experiments ( $\mathrm{C}$, right). $\beta$-actin was used as a loading control. Columns, means of three independent experiments; bars, S.E. * ${ }^{*} \mathrm{p}<0.05,{ }^{* *}, \mathrm{p}<0.01$. 


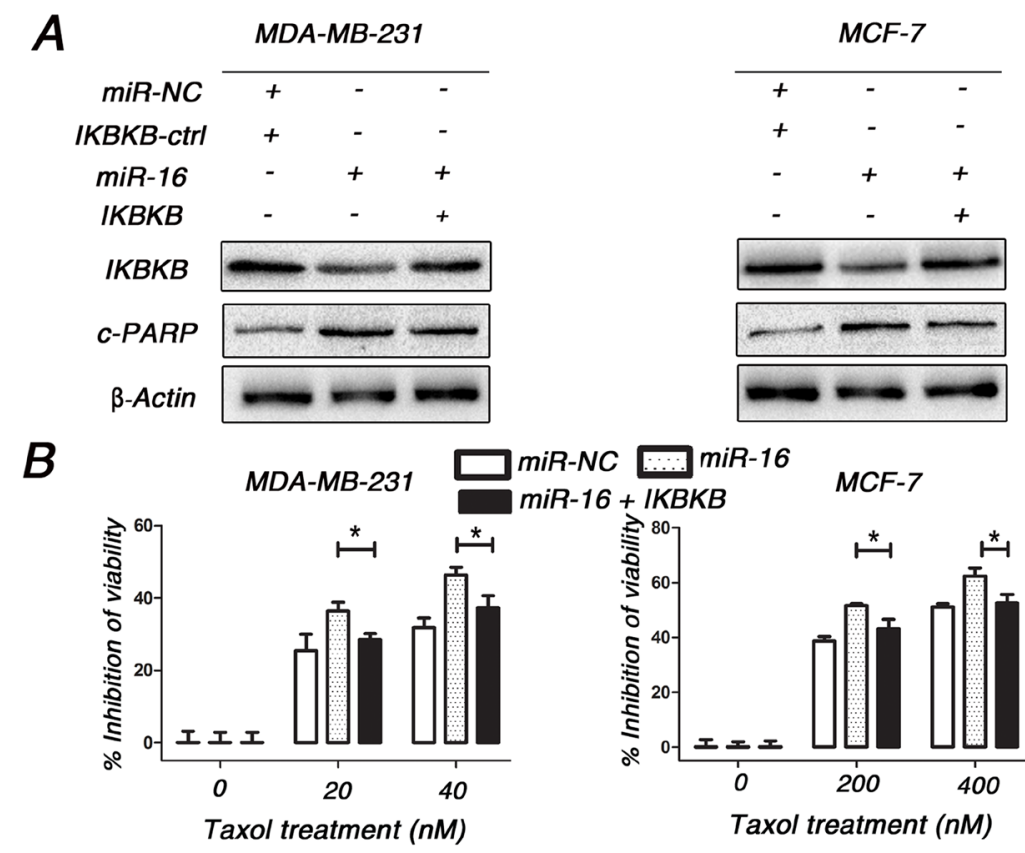

C
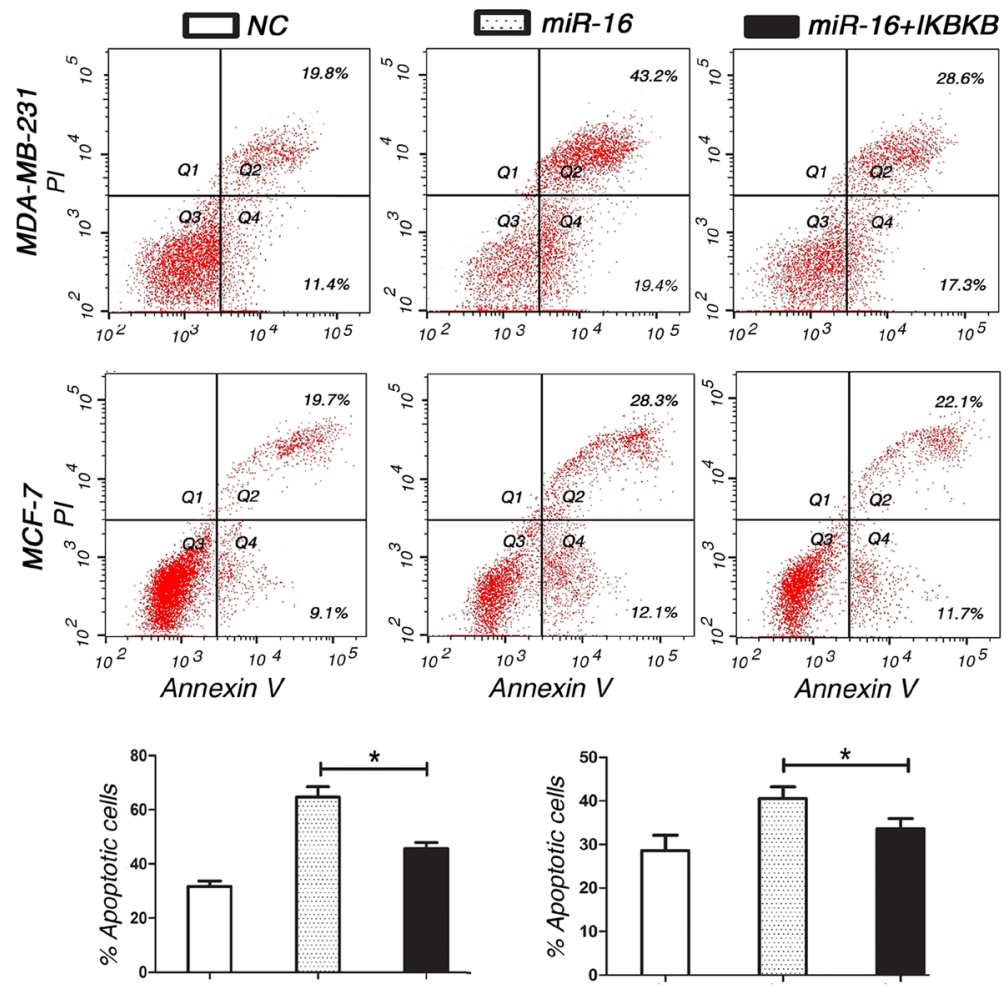

MDA-MB-231

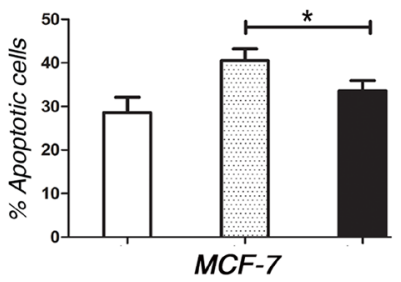

Figure 5: Restoring the expression of IKBKB recovers Taxol resistance and counteracts miR-16-mediated Taxol sensitivity. A. MDA-MB-231 and MCF-7 cells were transfected with miR-16 mimics alone or miR-16 mimics plus IKBKB overexpression plasmid and then treated with 40 and $400 \mathrm{nM}$ Taxol for $48 \mathrm{~h}$, respectively. Cell lysates were extracted for western blotting using antibodies against c-PARP and IKBKB. $\beta$-actin was used as a loading control. B. MDA-MB-231 and MCF-7 cells transfected with miR-16 mimics alone or miR-16 mimics plus IKBKB overexpression plasmid were seeded into 96-well plates and treated with 0, 20, $40 \mathrm{nM}$ (MDAMB-231) or 0, 200, $400 \mathrm{nM}$ (MCF-7) Taxol for $48 \mathrm{~h}$. The cell viabilities were then detected using MTT assays. Columns, means of three independent experiments; bars, S.E. *, p $<0.05$. C. MDA-MB-231 and MCF-7 cells were transfected with miR-16 mimics alone or miR16 mimics plus IKBKB overexpression plasmid and then treated with 40 and $400 \mathrm{nM}$ Taxol for $48 \mathrm{~h}$, respectively. Cells were collected for annexin V staining and flow cytometry assays. Percentages of apoptotic cells are represented in bar diagram from three independent experiments. Columns, means of three independent experiments; bars, S.E. *, $\mathrm{p}<0.05$. 
miR-16 target genes, which collectively conferred miR-16mediated Taxol sensitivity. These novel findings provide a unique insight into the molecular mechanism of miR-16mediated Taxol sensitivity.

$\mathrm{NF}-\kappa \mathrm{B}$ pathway is critical for the normal development of mammary gland by promoting proliferation, motility and invasion [35], abnormal activation of NF- $\kappa$ B pathway can be observed in breast cancer [36-39]. In addition, NF- $\kappa \mathrm{B}$ activation has been also implicated in cancer chemotherapy resistance mechanisms [40]. And inhibition of NF- $\mathrm{BB}$ pathway by either the IKK inhibitor PA or the proteasome inhibitor PS-341 is able to restore the anti-estrogenic effects of tamoxifen in breast cancer cells $[41,42]$. In the classical pathway, IKBKB activates NF- $\mathrm{KB}(\mathrm{p} 65)$ through phosphorylation of inhibitors of NF- $\kappa \mathrm{B}$ (I $\kappa \mathrm{Bs}$ ), thus leading to p65 nucleus translocation [43] and resulting in subsequent transcription of downstream genes involved in tumorigenesis and anti-apoptosis [44] including antiapoptotic (Bcl-2, Bcl-xL, survivin), proliferative (cyclin D1), proinflammatory (COX-2), invasive (MMP-9) and angiogenic (VEGF) genes. In our study, the protein level of p-p65 and NF- $\mathrm{KB}$ activation were found to be decreased after overexpression of miR-16 in breast cancer cells with Taxol treatment (Figure S3A and S3B). We propose that
miR-16 may promote apoptosis via an IKBKB-p65-Bcl-2 axis, resulting in chemosensitivity to Taxol, which still need further investigations and large patient samples to illustrate it.

To date, miR-16 has been identified to participate in tumorigenesis, development and progression, and it has been shown to be a tumor suppressor in different tumors [45-47]. Especially, miR-16 was validated to decrease cellular growth and proliferation and induce apoptosis in MCF-7 cells [47], implying that miR-16 might be involved in breast cancer development and progression. To confirm this hypothesis, we detected expression levels of miR-16 and IKBKB in breast cancer samples and found that miR-16 was negatively associated with $\mathrm{T}$ stages, while IKBKB positively correlated with $\mathrm{T}, \mathrm{N}$ and clinical stages, which supported that miR-16 and IKBKB might participate in tumorigenesis of breast cancer.

Taken together, we have shown that miR-16 is positively involved in Taxol-induced cell cytotoxicity and apoptosis in breast cancer cells. IKBKB was identified as a direct target of miR-16, restoring the expression of IKBKB in miR-16-ovexpressing breast cells could recover Taxol resistance. Furthermore, an inverse correlation between

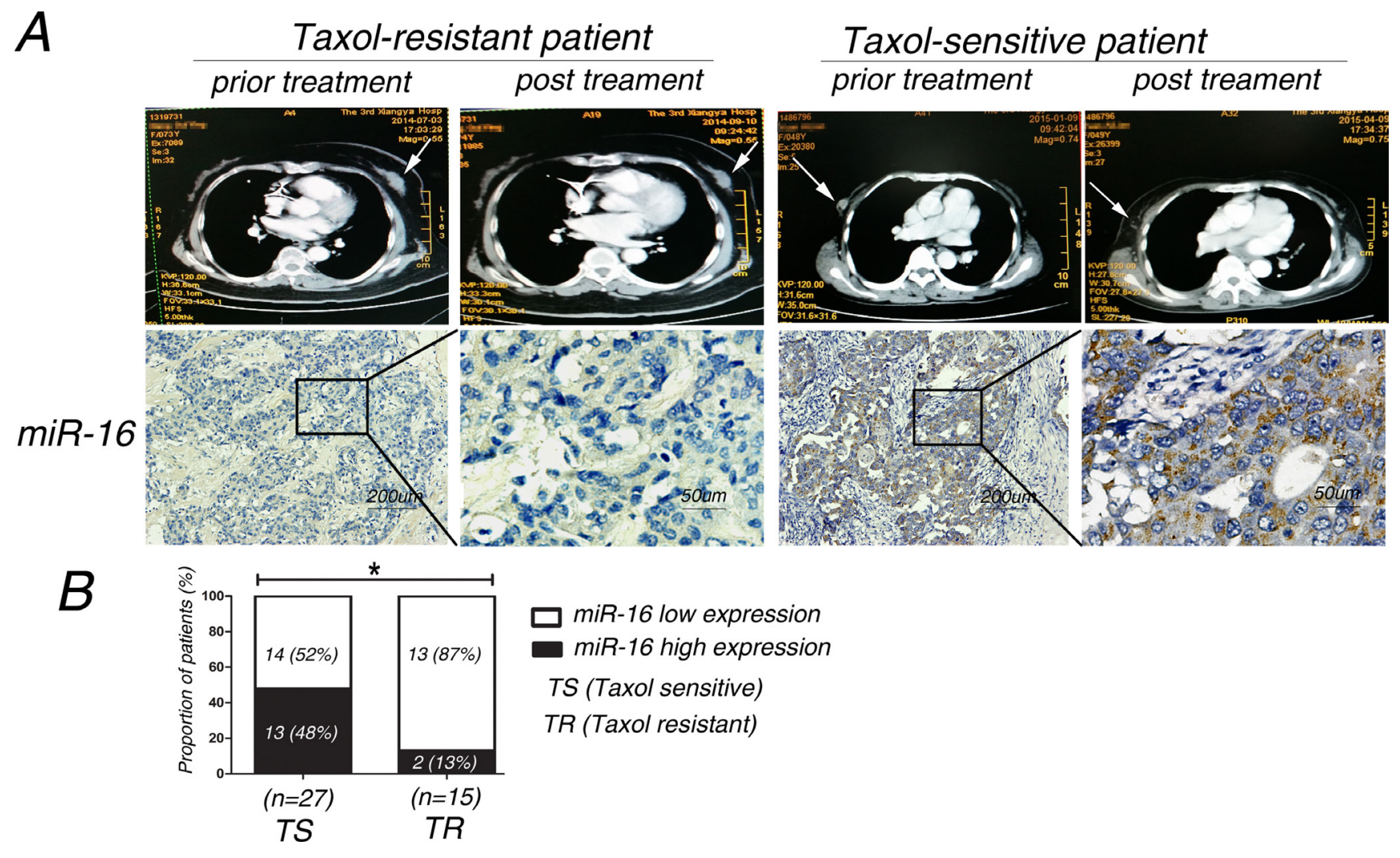

Figure 6: The expression level of miR-16 in Taxol-sensitive breast cancer tissues is higher than that in Taxolresistant tissues. A. miR-16 expression was measured by in situ hybridization in paraffin-embedded Taxol-treated breast cancer tissues. Representative cases of Taxol-sensitive $(n=27)$ and Taxol-resistant $(n=15)$ patients with high or low miR-16 staining are shown. B. Proportion of Taxol-treated breast cancer patients with low or high miR-16 expression. ${ }^{*}, \mathrm{p}<0.05$. 
$A$
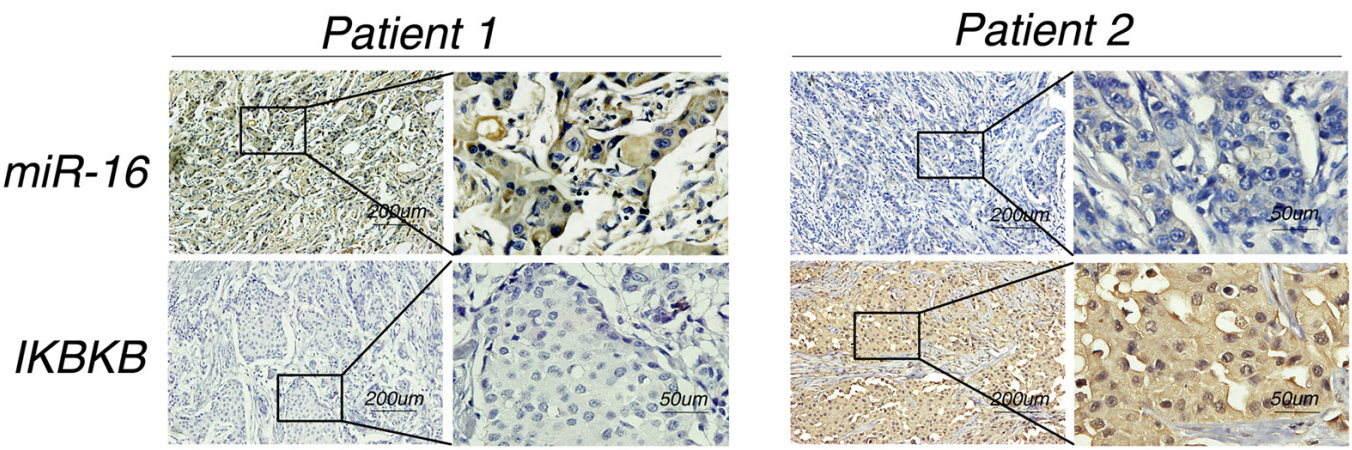

$B$

\begin{tabular}{ccc}
\hline & \multicolumn{2}{c}{ IKBKB } \\
\cline { 2 - 3 } miR-16 & low & high \\
\hline low & 10 & 53 \\
high & 25 & 2 \\
\hline \multicolumn{3}{c}{ Pearson correlation $=-0.721$} \\
P-value $<0.01$
\end{tabular}
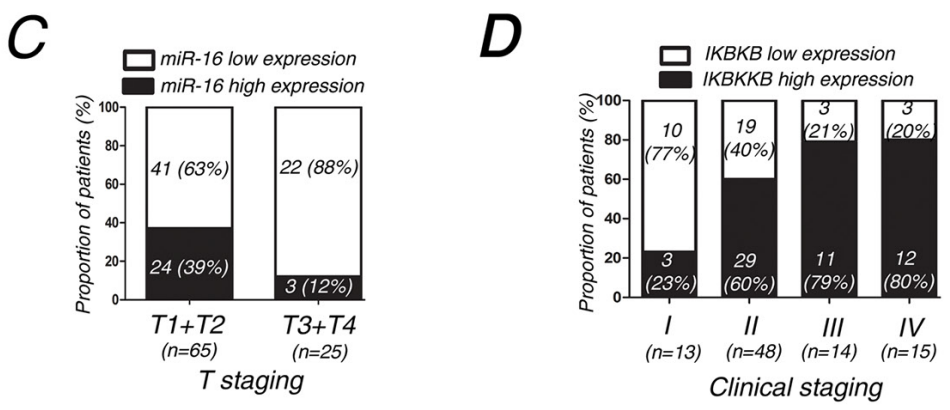

E

$\operatorname{miR}-16$

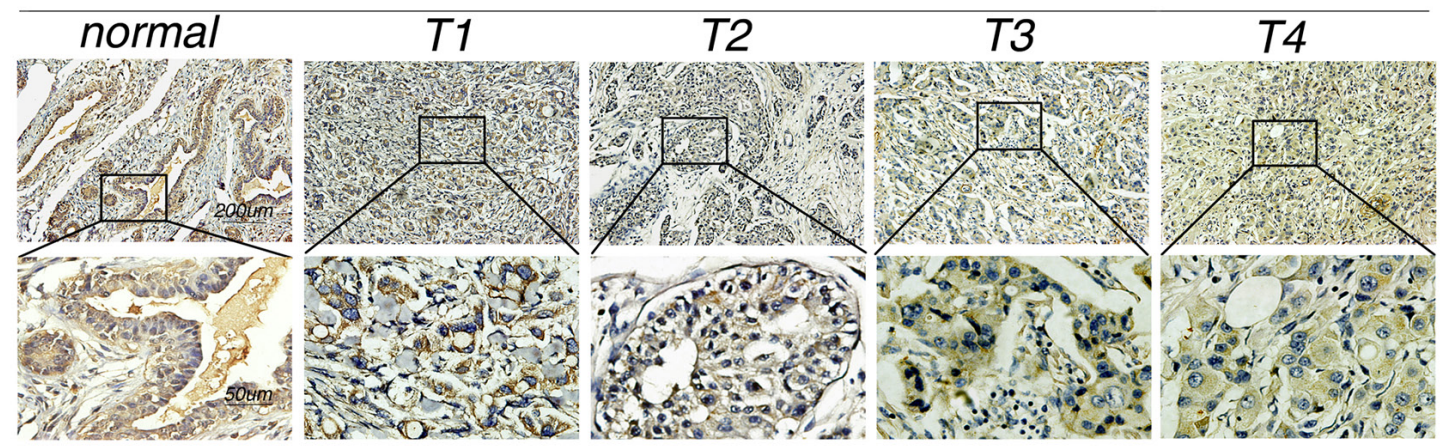

$F$

IKBKB

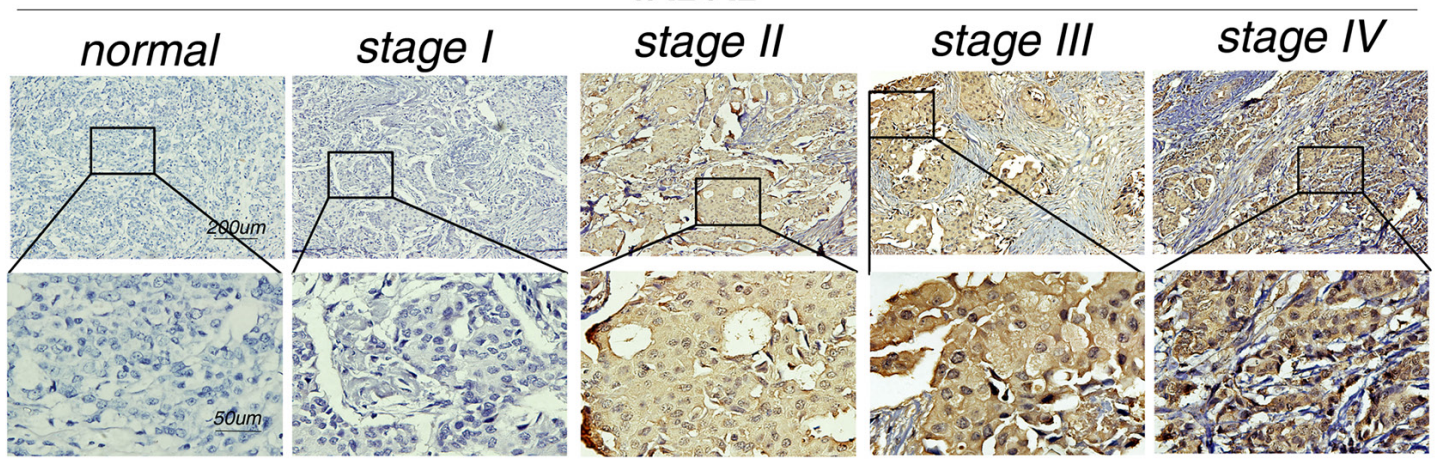

Figure 7: MiR-16 expression is inversely correlated with IKBKB expression and their expression levels are associated with clinicopathological characteristics of breast cancer patients. A. Representative images of inverse correlation between miR16 and IKBKB expression are shown. B. Spearman rank test of 90 breast cancer patients was used for depicting the correlation between miR-16 and IKBKB. C-D. Proportion of breast cancer patients with miR-16 expression and T stages (C) or IKBKB expression and clinical stages (D). E-F. Representative images of breast cancer patients with miR-16 expression and T stages (E) or IKBKB expression and clinical stages $(\mathrm{F})$. 
Table 1: Associations between miR-16 and IKBKB expression levels and the clinicopathological characteristics of breast cancer patients

\begin{tabular}{|c|c|c|c|c|c|c|c|}
\hline \multirow[b]{2}{*}{ Variables } & \multirow[b]{2}{*}{ Cases (n) } & \multicolumn{2}{|c|}{$\begin{array}{c}\text { miR-16 } \\
\text { Expression (n) }\end{array}$} & \multirow[b]{2}{*}{ P value } & \multicolumn{2}{|c|}{$\begin{array}{c}\text { IKBKB } \\
\text { Expression (n) }\end{array}$} & \multirow[b]{2}{*}{ P value } \\
\hline & & Low & High & & Low & High & \\
\hline Age (years) & & & & 0.129 & & & 0.060 \\
\hline$<50$ & 56 & 36 & 20 & & 26 & 30 & \\
\hline$\geq 50$ & 34 & 27 & 7 & & 9 & 25 & \\
\hline Pathological classification & & & & 0.275 & & & 0.351 \\
\hline Invasive ductal carcinoma & 59 & 44 & 15 & & 20 & 39 & \\
\hline Invasive lobular carcinoma & 16 & 11 & 5 & & 7 & 9 & \\
\hline Medullary carcinoma & 15 & 8 & 7 & & 8 & 7 & \\
\hline Pathological grade * & & & & 0.953 & & & 0.663 \\
\hline I & 8 & 6 & 2 & & 3 & 5 & \\
\hline II & 37 & 28 & 9 & & 11 & 26 & \\
\hline III & 14 & 10 & 4 & & 6 & 8 & \\
\hline T staging & & & & 0.021 & & & $<0.001$ \\
\hline $\mathrm{T} 1+\mathrm{T} 2$ & 65 & 41 & 24 & & 34 & 31 & \\
\hline $\mathrm{T} 3+\mathrm{T} 4$ & 25 & 22 & 3 & & 1 & 24 & \\
\hline Lymph node metastasis & & & & 0.059 & & & $<0.001$ \\
\hline No & 43 & 26 & 17 & & 27 & 16 & \\
\hline Yes & 47 & 37 & 10 & & 8 & 39 & \\
\hline Distant metastasis & & & & 0.537 & & & 0.100 \\
\hline No & 75 & 51 & 24 & & 32 & 43 & \\
\hline Yes & 15 & 12 & 3 & & 3 & 12 & \\
\hline Clinical staging & & & & 0.711 & & & 0.008 \\
\hline I & 13 & 8 & 5 & & 10 & 3 & \\
\hline II & 48 & 34 & 14 & & 19 & 29 & \\
\hline III & 14 & 9 & 5 & & 3 & 11 & \\
\hline IV & 15 & 12 & 3 & & 3 & 12 & \\
\hline
\end{tabular}

* The correlation between miR-16/IKBKB expression and pathological grade were only analyzed in 59 cases of Invasive ductal carcinoma patients.

miR-16 and IKBKB expression was found in breast cancer tissues, miR-16 was negatively associated with $T$ stages, whereas IKBKB was positively correlated with $\mathrm{T}$, $\mathrm{N}$ and clinical stages. Therefore, miR-16 sensitizes breast cancer cells to Taxol through the suppression of IKBKB expression, and it may potentially serve as a therapeutic target for overcoming Taxol resistance in human breast cancer.

\section{MATERIALS AND METHODS}

\section{Cells and human tissues}

Human breast cancer cell lines MDA-MB-231 and MCF-7 were maintained in our laboratory. MDAMB-231 cells were cultured in RPMI 1640 medium, and MCF-7 cells were cultured in DMEM medium in a 
humidified incubator with $5 \% \mathrm{CO}_{2}$ at $37^{\circ} \mathrm{C}$. Cell media was supplemented with $10 \%$ fetal bovine serum (FBS, Invitrogen, Shanghai, China) and penicillin/streptomycin.

All tissue samples were collected from diagnosed breast cancer patients who were confirmed by histopathological examination at the Third Xiangya Hospital (Changsha, China) from 1st Jan. 2004 to 30th Jun. 2015. Among the selected cases, 42 of the patients received Taxol-combined neoadjuvant chemotherapy and their sensitivity or resistance to Taxol were differentiated by computed tomography (CT) analysis before and after Taxol treatment, of which, 25 cases presented Taxolsensitive and 17 cases resistant.

This study was approved by the Research Ethics Board of the Third Xiangya Hospital and signed informed consent was obtained from each participant before they were enrolled in the study.

\section{Overexpression and knockdown of miR-16}

MDA-MB-231 and MCF-7 cells were seeded in 6-well plates, and on the following day, when the cells were approximately $70 \%$ confluent, they were transfected with $50 \mathrm{nM}$ miR-16 mimics (miR-16), $100 \mathrm{nM}$ miR-16 inhibitor (anti-miR-16), or equal amounts of scrambled negative control RNA (Ribobio, Guangzhou, China) using Lipofectamine 3000 (Invitrogen, Guangzhou, China). The cells were then harvested $24 \mathrm{~h}$ after transfection for quantitative RT-PCR and $48 \mathrm{~h}$ after transfection for western blot assays.

\section{Plasmid construction and overexpression of IKBKB}

A mammalian expression plasmid encoding the human IKBKB open reading frame (pGV219-IKBKB) was purchased from Genechem (Shanghai, China). An empty plasmid was served as a negative control. IKBKB expression plasmid and negative plasmid $(2 \mu \mathrm{g})$ were transfected into MDA-MB-231 and MCF-7 cells using Lipofectamine 3000 according to the manufacturer's instructions. Total RNA was isolated $24 \mathrm{~h}$ post-transfection for quantitative RT-PCR, and protein was extracted $48 \mathrm{~h}$ after transfection for the western blot assay.

\section{RNA isolation and quantitative RT-PCR}

Total RNA was extracted from cultured cells using TRIzol Reagent (Invitrogen, Shanghai, China) according to the manufacturer's instructions. Assays to quantify miRNAs were performed using the miRNA qRT-PCR Kit (Ribobio, Guangzhou, China). Briefly, $1 \mu \mathrm{g}$ of total RNA was added with Poly(A)-Tailing and reversetranscribed to cDNA using Reverse Transcriptase and Uni-Reverse Primer (Ribobio). The reaction conditions were as follows: $37^{\circ} \mathrm{C}$ for $60 \mathrm{~min}, 42^{\circ} \mathrm{C}$ for $60 \mathrm{~min}$, and $72{ }^{\circ} \mathrm{C}$ for $10 \mathrm{~min}$. Real-time PCR was performed using specific primers for miR-16 and U6 under the following conditions: $95^{\circ} \mathrm{C}$ for $10 \mathrm{~min}$, followed by 40 cycles of $95{ }^{\circ} \mathrm{C}$ for $10 \mathrm{~s}, 60{ }^{\circ} \mathrm{C}$ for $20 \mathrm{~s}$, and $70{ }^{\circ} \mathrm{C}$ for $1 \mathrm{~s}$. The sequences of the primers were as followings: miR-16, 5, primer (5-TAGCAGCACGTAAATATTGGCG-3) and 3' primer (provided by Ribobio); U6, 5' primer (5-ATTGGAACGATACAGAGAAGATT-3) and 3' primer (5-GGAACGCTTCACGAATTTG-3). All of the reactions were run in triplicate and the relative levels of miR-16 were normalized to U6.

To detect IKBKB mRNA levels, $2 \mu \mathrm{g}$ of total RNA was reverse-transcribed to cDNA using oligo(dT) and the Thermoscript kit (Thermo Scientific, Shanghai, China) under the following conditions: $42^{\circ} \mathrm{C}$ for $60 \mathrm{~min}$ and 70 ${ }^{\circ} \mathrm{C}$ for $5 \mathrm{~min}$. Next, real-time PCR was performed using the RT product, SYBER Green Dye (TaKaRa, Dalian, China) and specific primers for IKBKB and GAPDH. The sequences of the primers were as followings: IKBKB, 5' primer (5-TGAGAAGACTGTTGTCCGGC-3) and 3' primer (5-GCAGGGTGCAGAGGTTATGT-3); GAPDH, 5' primer (5-CGAGATCCCTCCAAAATCAA-3) and 3 , primer (5-TTCACACCCATGACGAACAT-3). The reactions were incubated at $95{ }^{\circ} \mathrm{C}$ for $3 \mathrm{~min}$, followed by 40 cycles of $95^{\circ} \mathrm{C}$ for $10 \mathrm{~s}, 60{ }^{\circ} \mathrm{C}$ for $30 \mathrm{~s}$, and $72^{\circ} \mathrm{C}$ for $30 \mathrm{~s}$. All of the reactions were run in triplicate and the relative amount of IKBKB mRNA was normalized to GAPDH.

\section{Protein extraction and western blot assay}

All cells were rinsed with PBS (pH 7.4) and lysed in RIPA Lysis buffer (Beyotime, China) supplemented with a protease and phosphatase inhibitor Cocktail (Thermo Scientific 78440) on ice for $30 \mathrm{~min}$. Cell lysates were cleared by centrifugation at $14,000 \mathrm{~g}$ at $4{ }^{\circ} \mathrm{C}$ for $20 \mathrm{~min}$. Supernatants were collected, and protein concentrations were calculated using a Pierce BCA protein assay kit (Thermo Scientific). Proteins samples $(50 \mu \mathrm{g})$ were separated by $10 \%$ sodium dodecylsulfate-polyacrylamide gel electrophoresis (SDS-PAGE) and then transferred onto a PVDF membrane. Membranes were incubated overnight at $4{ }^{\circ} \mathrm{C}$ with primary anti-IKBKB (dilution 1:200, \#209791-AP, Proteintech, Wuhan, China) and anti-cleaved PARP (dilution 1:1000, \#5625, Cell Signaling, Shanghai, China) antibody. The next day, Membranes were washed with PBS and then incubated with a horseradish peroxidase-conjugated secondary antibody for $1 \mathrm{~h}$ at room temperature. The signal was visualized using an ECL detection reagent and quantified by densitometry using the Image J software (http://rsb.info.nih.gov/ij). Beta-actin was used as a loading control and detected using mouse anti- $\beta$-Actin antibody (dilution 1:2000, \#AM10128, Abgent, Suzhou, China). 


\section{Cell proliferation assay}

MDA-MB-231 $\left(8 \times 10^{3} /\right.$ well $)$ and MCF-7 $\left(5 \times 10^{3 /}\right.$ well) cells were cultivated in 96-well plates and treated with Taxol for $48 \mathrm{~h}$. MTT solution $(0.5 \mathrm{mg} / \mathrm{ml})$ was added to each well and incubation was continued for $4 \mathrm{~h}$ at $37^{\circ} \mathrm{C}$. DMSO (100 $\mu$ l. Sigma) was then added to solute the dye and the absorbance was recorded at $490 \mathrm{~nm}$. All tests were performed in triplicate. The inhibitory rate of Taxol-treated cells was normalized to that of Taxol-untreated cells and calculated by the following equation: inhibitory rate of cells $=((\mathrm{OD}$ of untreated wells $-\mathrm{OD}$ of treated wells $) / \mathrm{OD}$ of untreated wells $) \times 100 \%$.

\section{Apoptosis assay}

MDA-MB-231 and MCF-7 cells were transfected with miR-16 mimics, miR-16 inhibitor, IKBKB overexpression plasmid, or miR-16 mimics plus IKBKB overexpression plasmid and then treated with indicated concentrations of Taxol for $48 \mathrm{~h}$ to induce apoptosis. The miR-control, anti-miR-control and control plasmid were served as negative controls. Both of the attached and floating cells were harvested and flow cytometry analysis was performed using an Annexin V-FITC/PI staining kit (BD Biosciences, CA, USA) according to the manufacturer's instructions. All experiments were performed in triplicate.

\section{Luciferase reporter assay}

For the luciferase reporter assay of miRNA binding site, the wild-type or mutant IKBKB 3'-UTRs (from UGCUGCU to ACGACGA) were cloned into the pMIR-reporter plasmid immediately downstream of the firefly luciferase gene. All of the luciferase constructs were verified by sequencing. MDA-MB-231 and MCF7 cells were transiently co-transfected with pMIRIKBKB-3'UTR-wt or pMIR-IKBKB-3'UTR-mut, renilla luciferase plasmid ( $\mathrm{pRL}-\mathrm{TK}$ vector), miR-16 mimics or miR-16 inhibitor using Lipofectamine 3000 transfection reagent according to the manufacturer's protocol. After $48 \mathrm{~h}$ of transfection, cells were harvested and luciferase activities were determined using the Promega dual luciferase reporter assay kit. pRL-TK vector was used as the internal control. The relative luciferase activities were calculated by the ratio of firefly luc/ renilla luc activity and normalized to that of the control cells.

As for the luciferase reporter assay of NF- $\mathrm{KB}$ regulation, MDA-MB-231 and MCF-7 were co-transfected with $50 \mathrm{nM}$ miR-Neg or miR-16 mimics, pNF-кBLuc construct (stored in our lab) and pRL-TK plasmid (Promega, Madison, WI, USA) using Lipofectamine 3000 reagent. Luciferase activity was measured after treatment with $40 \mathrm{nM}$ (MDA-MB-231) or $400 \mathrm{nM}$ (MCF-7) Taxol for $24 \mathrm{~h}$, respectively. The pRL-TK was used as an internal control. The results were expressed as relative luciferase activity (firefly luc/renilla luc).

\section{In situ hybridization (ISH) analysis}

In situ hybridization was performed to detect miR-16 expression in tissue specimens. The probes were synthesized and labeled with DIG-dUTP at the 5, end (Sangon Biotech, Shanghai, China). Hybridization, washing, and scanning were performed according to the manufacturer's instructions. Two independent pathologists who were blinded to the clinicopathological information scored the samples. The staining intensity was scored as 0 (negative), $1(+), 2(++)$, and $3(+++)$. The extent of staining was scored as $0 \sim 1.0(0 \% \sim 100 \%)$. The final staining score $(0-3)$ was calculated as the multiplication of the intensity score and extent score. The final score $\geq 1$ was defined as high expression, otherwise was defined as low expression [48].

\section{Immunohistochemical (IHC) staining}

IHC staining was performed using an UltraSensitive SP Kit (Maixin Biotechnology Company, Fuzhou, China). The staining was developed using DAB as the chromogen. The slides were counterstained with Mayer's hematoxylin and mounted for evaluation under a microscope. Two independent pathologists who were blinded to the clinicopathological information scored the samples. The score was judged by the multiplication of the intensity score and extent score similar to that used in the in situ hybridization analysis described above.

\section{Statistical analysis}

Statistical analysis was performed by using SPSS software, version 19.0 (SPSS, Chicago, IL, USA) and GraphPad Prism 5. Student's $t$-test was used to evaluate significant differences between any two groups of data, and one way ANOVA test was used to evaluate significant differences for multiple comparisons. Kruskal-Wallis $\mathrm{H}$ test was used to evaluate significant differences for ranked data. Correlation analysis was performed using the Spearman method. Data were shown as the means \pm standard error (S.E.) The value of $\mathrm{p}<0.05$ was considered significant.

\section{CONFLICTS OF INTEREST}

The authors declare no conflicts of interest.

\section{GRANT SUPPORT}

This work was supported by grants obtained from the National Natural Science Foundation of China (Nos. 81328019, 81572748, 81472286). 


\section{REFERENCES}

1. Siegel R, Naishadham D, Jemal A. Cancer statistics, 2013. CA Cancer J Clin. 2013; 63:11-30.

2. McGrogan BT, Gilmartin B, Carney DN, McCann A. Taxanes, microtubules and chemoresistant breast cancer. Biochim Biophys Acta. 2008; 1785:96-132.

3. Gluck S. nab-Paclitaxel for the treatment of aggressive metastatic breast cancer. Clin Breast Cancer. 2014; 14:221-27.

4. Ferlini C, Cicchillitti L, Raspaglio G, Bartollino S, Cimitan S, Bertucci C, Mozzetti S, Gallo D, Persico M, Fattorusso C, Campiani G, Scambia G. Paclitaxel directly binds to Bcl-2 and functionally mimics activity of Nur77. Cancer Res. 2009; 69:6906-14.

5. Haldar S, Chintapalli J, Croce CM. Taxol induces bcl-2 phosphorylation and death of prostate cancer cells. Cancer Res. 1996; 56:1253-55.

6. Greenberger LM, Lothstein L, Williams SS, Horwitz SB. Distinct P-glycoprotein precursors are overproduced in independently isolated drug-resistant cell lines. Proc Natl Acad Sci U S A. 1988; 85:3762-66.

7. Oguri T, Ozasa H, Uemura T, Bessho Y, Miyazaki M, Maeno K, Maeda H, Sato S, Ueda R. MRP7/ABCC10 expression is a predictive biomarker for the resistance to paclitaxel in non-small cell lung cancer. Mol Cancer Ther. 2008; 7:1150-55.

8. Lee JH, Kim C, Sethi G, Ahn KS. Brassinin inhibits STAT3 signaling pathway through modulation of PIAS-3 and SOCS-3 expression and sensitizes human lung cancer xenograft in nude mice to paclitaxel. Oncotarget. 2015; 6:6386-6405. doi: 10.18632/oncotarget.3443.

9. Chen CH, Cheng CT, Yuan Y, Zhai J, Arif M, Fong LW, $\mathrm{Wu}$ R, Ann DK. Elevated MARCKS phosphorylation contributes to unresponsiveness of breast cancer to paclitaxel treatment. Oncotarget. 2015; 6:15194-15208. doi: 10.18632/oncotarget.3827.

10. Dumontet $\mathrm{C}$, Isaac $\mathrm{S}$, Souquet $\mathrm{PJ}$, Bejui-Thivolet $\mathrm{F}$, Pacheco Y, Peloux N, Frankfurter A, Luduena R, Perol M. Expression of class III beta tubulin in non-small cell lung cancer is correlated with resistance to taxane chemotherapy. Bull Cancer. 2005; 92:E25-30.

11. Mozzetti S, Ferlini C, Concolino P, Filippetti F, Raspaglio G, Prislei S, Gallo D, Martinelli E, Ranelletti FO, Ferrandina G, Scambia G. Class III beta-tubulin overexpression is a prominent mechanism of paclitaxel resistance in ovarian cancer patients. Clin Cancer Res. 2005; 11:298-305.

12. Bartel DP. MicroRNAs: target recognition and regulatory functions. Cell. 2009; 136:215-33.

13. Shivdasani RA. MicroRNAs: regulators of gene expression and cell differentiation. Blood. 2006; 108:3646-53.

14. Zhou M, Liu Z, Zhao Y, Ding Y, Liu H, Xi Y, Xiong W, Li G, Lu J, Fodstad O, Riker AI, Tan M. MicroRNA-125b confers the resistance of breast cancer cells to paclitaxel through suppression of pro-apoptotic Bcl-2 antagonist killer 1 (Bak1) expression. J Biol Chem. 2010; 285:21496-507.

15. Yang Q, Wang Y, Lu X, Zhao Z, Zhu L, Chen S, Wu Q, Chen C, Wang Z. MiR-125b regulates epithelialmesenchymal transition via targeting Sema4C in paclitaxelresistant breast cancer cells. Oncotarget. 2015; 6:32683279. doi: 10.18632/oncotarget.3065.

16. Liu X, Tang H, Chen J, Song C, Yang L, Liu P, Wang N, Xie X, Lin X, Xie X. MicroRNA-101 inhibits cell progression and increases paclitaxel sensitivity by suppressing MCL-1 expression in human triple-negative breast cancer. Oncotarget. 2015; 6:20070-20083. doi: 10.18632/oncotarget.4039.

17. Lerner M, Harada M, Loven J, Castro J, Davis Z, Oscier D, Henriksson M, Sangfelt O, Grander D, Corcoran MM. DLEU2, frequently deleted in malignancy, functions as a critical host gene of the cell cycle inhibitory microRNAs miR-15a and miR-16-1. Exp Cell Res. 2009; 315:2941-52.

18. Bonci D, Coppola V, Musumeci M, Addario A, Giuffrida R, Memeo L, D'Urso L, Pagliuca A, Biffoni M, Labbaye C, Bartucci M, Muto G, Peschle C, et al. The miR-15amiR-16-1 cluster controls prostate cancer by targeting multiple oncogenic activities. Nat Med. 2008; 14:1271-77.

19. Rivas MA, Venturutti L, Huang YW, Schillaci R, Huang TH, Elizalde PV. Downregulation of the tumor-suppressor miR-16 via progestin-mediated oncogenic signaling contributes to breast cancer development. Breast Cancer Res. 2012; 14:R77.

20. Linsley PS, Schelter J, Burchard J, Kibukawa M, Martin MM, Bartz SR, Johnson JM, Cummins JM, Raymond CK, Dai H, Chau N, Cleary M, Jackson AL, et al. Transcripts targeted by the microRNA-16 family cooperatively regulate cell cycle progression. Mol Cell Biol. 2007; 27:2240-52.

21. Liu Q, Fu H, Sun F, Zhang H, Tie Y, Zhu J, Xing R, Sun Z, Zheng X. miR-16 family induces cell cycle arrest by regulating multiple cell cycle genes. Nucleic Acids Res. 2008; 36:5391-404.

22. Ofir R, Seidman R, Rabinski T, Krup M, Yavelsky V, Weinstein Y, Wolfson M. Taxol-induced apoptosis in human SKOV3 ovarian and MCF7 breast carcinoma cells is caspase-3 and caspase-9 independent. Cell Death Differ. 2002; 9:636-42.

23. Wu W, Hodges E, Hoog C. Thorough validation of siRNAinduced cell death phenotypes defines new anti-apoptotic protein. Nucleic Acids Res. 2006; 34:e13.

24. Boulares AH, Yakovlev AG, Ivanova V, Stoica BA, Wang G, Iyer S, Smulson M. Role of poly(ADP-ribose) polymerase (PARP) cleavage in apoptosis. Caspase 3-resistant PARP mutant increases rates of apoptosis in transfected cells. J Biol Chem. 1999; 274:22932-22940.

25. Bivona TG, Hieronymus H, Parker J, Chang K, Taron M, Rosell R, Moonsamy P, Dahlman K, Miller VA, Costa C, 
Hannon G, Sawyers CL. FAS and NF-kappaB signalling modulate dependence of lung cancers on mutant EGFR. Nature. 2011; 471:523-26.

26. Cittelly DM, Das PM, Salvo VA, Fonseca JP, Burow ME, Jones FE. Oncogenic HER2\{Delta\}16 suppresses miR-15a/16 and deregulates BCL-2 to promote endocrine resistance of breast tumors. Carcinogenesis. 2010; 31:2049-57.

27. Huang N, Wu J, Qiu W, Lyu Q, He J, Xie W, Xu N, Zhang Y. MiR-15a and miR-16 induce autophagy and enhance chemosensitivity of Camptothecin. Cancer Biol Ther. 2015; 16:941-48.

28. Cimmino A, Calin GA, Fabbri M, Iorio MV, Ferracin M, Shimizu M, Wojcik SE, Aqeilan RI, Zupo S, Dono M, Rassenti L, Alder H, Volinia S, et al. miR-15 and miR-16 induce apoptosis by targeting BCL2. Proc Natl Acad Sci U S A. 2005; 102:13944-49.

29. Romieu-Mourez R, Landesman-Bollag E, Seldin DC, Traish AM, Mercurio F, Sonenshein GE. Roles of IKK kinases and protein kinase CK2 in activation of nuclear factor-kappaB in breast cancer. Cancer Res. 2001; 61:3810-18.

30. Yang J, Richmond A. Constitutive IkappaB kinase activity correlates with nuclear factor-kappaB activation in human melanoma cells. Cancer Res. 2001; 61:4901-09.

31. Baumgartner B, Weber M, Quirling M, Fischer C, Page S, Adam M, Von Schilling C, Waterhouse C, Schmid C, Neumeier D, Brand K. Increased IkappaB kinase activity is associated with activated NF-kappaB in acute myeloid blasts. Leukemia. 2002; 16:2062-71.

32. Li L, Aggarwal BB, Shishodia S, Abbruzzese J, Kurzrock R. Nuclear factor-kappaB and IkappaB kinase are constitutively active in human pancreatic cells, and their down-regulation by curcumin (diferuloylmethane) is associated with the suppression of proliferation and the induction of apoptosis. Cancer. 2004; 101:2351-62.

33. Hu MC, Lee DF, Xia W, Golfman LS, Ou-Yang F, Yang JY, Zou Y, Bao S, Hanada N, Saso H, Kobayashi R, Hung MC. IkappaB kinase promotes tumorigenesis through inhibition of forkhead FOXO3a. Cell. 2004; 117:225-37.

34. Song L, Huang Q, Chen K, Liu L, Lin C, Dai T, Yu C, Wu Z, Li J. miR-218 inhibits the invasive ability of glioma cells by direct downregulation of IKK-beta. Biochem Biophys Res Commun. 2010; 402:135-40.

35. Cao Y, Karin M. NF-kappaB in mammary gland development and breast cancer. J Mammary Gland Biol Neoplasia. 2003; 8:215-223.

36. Baldwin AJ. Series introduction: the transcription factor NF-kappaB and human disease. J Clin Invest. 2001; 107:3-6.
37. Veiby OP, Read MA. Chemoresistance: impact of nuclear factor (NF)-kappaB inhibition by small interfering RNA. Commentary re J. Guo et al., Enhanced chemosensitivity to irinotecan by RNA interference-mediated downregulation of the NF-kappaB p65 subunit. Clin Cancer Res 2004;10:3333-3341. Clin Cancer Res. 2004; 10:3262-3264.

38. Ghosh S, Karin M. Missing pieces in the NF-kappaB puzzle. Cell. 2002; 109 Suppl:S81-96.

39. Chen LF, Greene WC. Shaping the nuclear action of NF-kappaB. Nat Rev Mol Cell Biol. 2004; 5:392-401.

40. Wang CY, Cusack JJ, Liu R, Baldwin AJ. Control of inducible chemoresistance: enhanced anti-tumor therapy through increased apoptosis by inhibition of NF-kappaB. Nat Med. 1999; 5:412-417.

41. Zhou Y, Eppenberger-Castori S, Marx C, Yau C, Scott GK, Eppenberger U, Benz CC. Activation of nuclear factor-kappaB (NFkappaB) identifies a high-risk subset of hormone-dependent breast cancers. Int J Biochem Cell Biol. 2005; 37:1130-1144.

42. Zhou Y, Eppenberger-Castori S, Eppenberger U, Benz CC. The NFkappaB pathway and endocrine-resistant breast cancer. Endocr Relat Cancer. 2005; 12 Suppl 1:S37-S46.

43. Annunziata CM, Davis RE, Demchenko Y, Bellamy W, Gabrea A, Zhan F, Lenz G, Hanamura I, Wright G, Xiao W, Dave S, Hurt EM, Tan B, et al. Frequent engagement of the classical and alternative NF-kappaB pathways by diverse genetic abnormalities in multiple myeloma. Cancer Cell. 2007; 12:115-30.

44. Aggarwal BB. Nuclear factor-kappaB: the enemy within. Cancer Cell. 2004; 6:203-08.

45. Renjie W, Haiqian L. MiR-132, miR-15a and miR-16 synergistically inhibit pituitary tumor cell proliferation, invasion and migration by targeting Sox5. Cancer Lett. 2015; 356:568-78.

46. Kang W, Tong JH, Lung RW, Dong Y, Zhao J, Liang Q, Zhang L, Pan Y, Yang W, Pang JC, Cheng AS, Yu J, To KF. Targeting of YAP1 by microRNA-15a and microRNA-16-1 exerts tumor suppressor function in gastric adenocarcinoma. Mol Cancer. 2015; 14:52.

47. Mobarra N, Shafiee A, Rad SM, Tasharrofi N, SoufiZomorod M, Hafizi M, Movahed M, Kouhkan F, Soleimani M. Overexpression of microRNA-16 declines cellular growth, proliferation and induces apoptosis in human breast cancer cells. In Vitro Cell Dev Biol Anim. 2015; 51:604-11.

48. Luo Y, Wang X, Wang H, Xu Y, Wen Q, Fan S, Zhao R, Jiang S, Yang J, Liu Y, Li X, Xiong W, Ma J, Peng S, Zeng Z, Li X, Phillips JB, Li G, Tan M, Zhou M. High Bak Expression Is Associated with a Favorable Prognosis in Breast Cancer and Sensitizes Breast Cancer Cells to Paclitaxel. Plos One. 2015; 10:e138955. 